AIAA Space 2010 Conference; Aug 31-Sep 2, 2010; Anaheim, CA

Session: Space Systems Engineering and Space Economics

Track: Space Workforce Development Issues and Industrial Base Challenges

\title{
Getting to First Flight: Equipping Space Engineers to Break the Start-Stop-Restart Cycle
}

\author{
Christopher E. Singer, Deputy Director \\ Daniel L. Dumbacher, Director \\ Engineering Directorate \\ NASA Marshall Space Flight Center
}

\begin{abstract}
The National Aeronautics and Space Administration's (NASA's) history is built on a foundation of can-do strength, while pointing to the Saturn/Apollo Moon missions in the 1960s and 1970s as its apex - a sentiment that often overshadows the potential that lies ahead. The chronicle of America's civil space agenda is scattered with programs that got off to good starts with adequate resources and vocal political support but that never made it past a certain milestone review, General Accountability Office report, or Congressional budget appropriation. Over the decades since the fielding of the Space Shuttle in the early 1980s, a start-stop-restart cycle has intervened due to many forces. Despite this impediment, the workforce has delivered engineering feats such as the International Space Station and numerous Shuttle and science missions, which reflect a trend in the early days of the Exploration Age that called for massive infrastructure and matching capital allocations. In the new millennium, the aerospace industry must respond to transforming economic climates, the public will, national agendas, and international possibilities relative to scientific exploration beyond Earth's orbit. Two pressing issues - workforce transition and mission success - are intertwined. As this paper will address, U.S. aerospace must confront related workforce development and industrial base issues head on to take space exploration to the next level. This paper also will formulate specific strategies to equip space engineers to move beyond the seemingly constant start-stop-restart mentality to plan and execute flight projects that actually fly.
\end{abstract}

In general, U.S. aerospace entities face the same workforce development challenges - from pending retirements to a lack of new hires. Many mid-career employees have never flown hardware or operated an experiment in space, which are rewards that motivate personnel, wherever they are on their career paths. This paper surveys the current aerospace environment and posits potential solutions to the ever-present recruitment and retention challenge by equipping the industry as a whole to weather and break the start-stop-restart cycle to which it has been continually subjected to over the last few decades. To retain the top-quality engineers who form the backbone of the nation's aerospace capability, it is critical that strategic plans be followed with demonstrable action. It is also vital that the government reduce the time to market by delivering incremental products to its stakeholders, rather than an all-or-nothing approach. The recent Ares I-X mission in October 2009 is a prime example of the power of testing to train the workforce, generate technical data from real-world flight profiles, and deliver visible value to stakeholders, while blazing a path forward toward getting to first flight. 


\title{
Getting to First Flight: Equipping Space Engineers to Break the Start-Stop-Restart Cycle
}

\author{
Christopher E. Singer** and Daniel L. Dumbacher† \\ NASA Marshall Space Flight Center \\ Marshall Space Flight Center, AL 35812
}

\begin{abstract}
The National Aeronautics and Space Administration's (NASA's) history is built on a foundation of can-do strength, while pointing to the Saturn/Apollo Moon missions in the 1960s and 1970s as its apex — a sentiment that often overshadows the potential that lies ahead. The chronicle of America's civil space agenda is scattered with programs that got off to good starts with adequate resources and vocal political support but that never made it past a certain milestone review, General Accountability Office report, or Congressional budget appropriation. Over the decades since the fielding of the Space Shuttle in the early 1980s, a start-stop-restart cycle has intervened due to many forces. Despite this impediment, the workforce has delivered engineering feats such as the International Space Station and numerous Shuttle and science missions, which reflect a trend in the early days of the Exploration Age that called for massive infrastructure and matching capital allocations. In the new millennium, the aerospace industry must respond to transforming economic climates, the public will, national agendas, and international possibilities relative to scientific exploration beyond Earth's orbit. Two pressing issues - workforce transition and mission success - are intertwined. As this paper will address, U.S. aerospace must confront related workforce development and industrial base issues head on to take space exploration to the next level. This paper also will formulate specific strategies to equip space engineers to move beyond the seemingly constant start-stop-restart mentality to plan and execute flight projects that actually fly.
\end{abstract}

*Deputy Director, Engineering Directorate/ED01, AIAA Member.

$\dagger$ Director, Engineering Directorate/ED01. 


\section{Introduction}

In general, U.S. aerospace entities face the same workforce development challenges - from pending retirements to a lack of new hires. The study "Launching the $21^{\text {st }}$ Century American Aerospace Workforce" states: "The generation of aerospace talent that won the Space Race and the Cold War is reaching retirement age, and America is not producing the number and quality of engineers, designers and technicians needed to even begin replacing those who have served so well." "This is such a risk that it is clearly addressed in the Civil Space Guidelines in the National Space Policy released June 2010. ${ }^{2}$

Many mid-career employees have never had the opportunity to fly hardware or operate an experiment in space, which are rewards that motivate personnel, wherever they are on their career paths. This paper surveys the current aerospace environment and posits potential solutions to the ever-present recruitment and retention challenge by equipping the industry as a whole to weather and break the start-stop-restart cycle to which it has been continually subjected over the last few decades.

To retain the top-quality engineers who form the backbone of the nation's aerospace capability, it is critical that strategic plans be followed with demonstrable action. It is also vital that the government reduce the time to market by delivering incremental products to its stakeholders, rather than an all-or-nothing approach. The recent Ares I-X mission in October 2009 is a prime example of the power of testing to train the workforce, generate technical data from real-world flight profiles, and deliver visible value to stakeholders, while blazing a path forward toward getting to first flight (Figure 1).

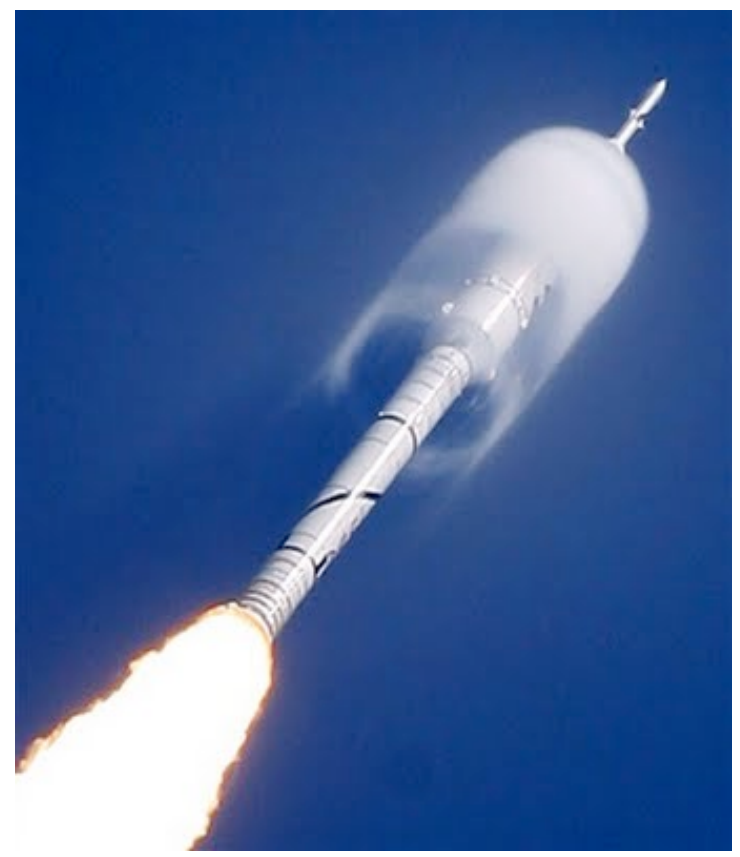

Figure 1. The Ares I-X flight demonstration was conducted in October 2009. 


\section{Mantras and Missions}

Throughout America's 50 years of space flight, the aerospace community has been motivated by, and subjected to, mantras that range the full spectrum of advice - from the 1960s action cry "Failure is not an option!" (Figure 2) to the less-than-optimum business battle cry of "faster-better-cheaper" in the 1990s, and back to "mission success" after the Mars Climate Orbiter and Mars Polar Lander failures. Discriminating between the testing-to-understand activities during the design and development phase - with some expected failures as part of the process - versus validating the system in later phases, has become somewhat of a lost art.

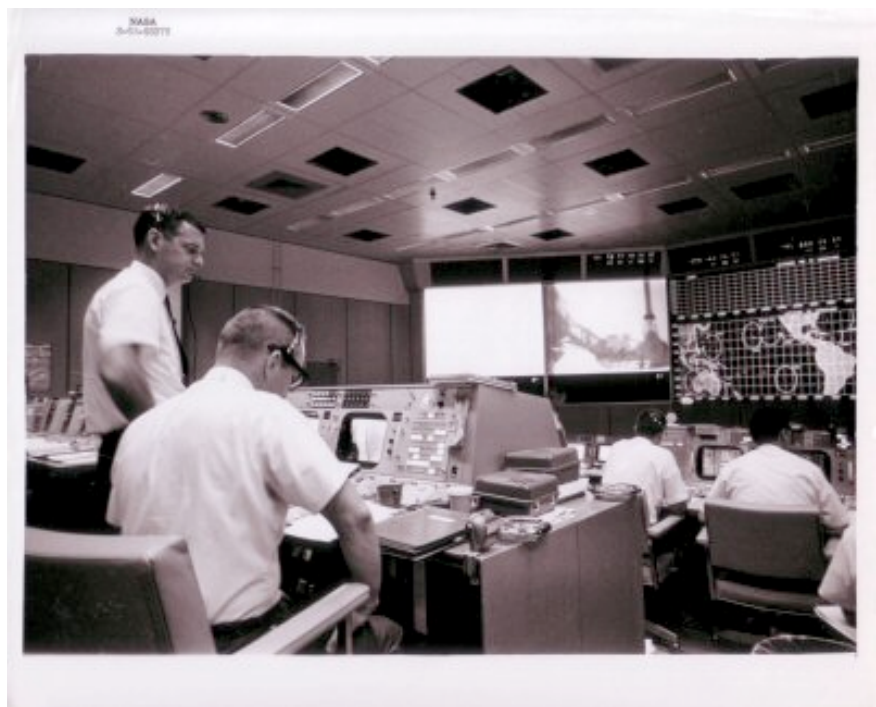

Figure 2. Apollo mission control.

While there have been numerous successes, too many to enumerate, it is the catastrophic failures that get the most attention and live within the collective consciousness of space engineers in the private and commercial sectors. The tragic losses of the Challenger and Columbia Shuttles and their valiant crews affect every safety decision and make progress slowly measured and painstakingly tracked. To be clear, when dealing with human safety, failure is not an option. Conversely, when developing a new space transportation system, testing to failure is often the best or only way to validate the analytical math models on which space engineers rely. Planning programmatic content to effectively play on these realities is one method to equip aerospace engineers to recognize that the start-stop-restart cycle is political in nature and to break the mental model that masks real progress despite the pantheon of program and project names.

This philosophical whipsaw effect, in combination with tragic social and political losses, has caused both the programmatic and institutional climate to avoid taking the risks that come with doing things that have never been done before. Although failures cannot be built into a budget, they naturally occur whether accounted for or not. Managing content such that reserves are available when the inevitable happens is a risk-reduction strategy that can help aerospace engineers analyze failures instead of declaring defeat. 
For scientific spacecraft and propulsion and transportation technology research and developments, the landscape is littered with the lessons taught by the 1998 Mars Climate Orbiter, which failed because of basic human error and lack of communication about technical standards, to the 1995 vintage X-33 flight demonstrator vehicle, which pushed the farthest boundaries of composite tank technologies (Figure 3) in a risky bid to field a single-stageto-orbit reusable launch vehicle. During the 2001-04 Space Launch Initiative (SLI) Program, the Space Shuttle was set for fundamental upgrades and improvements conducted in parallel with designing a new space transportation architecture and investing in long-lead enabling technologies, but those efforts were cut when SLI was cancelled in favor of the Orbital Space Plane and Next Generation Launch Technologies programs - both later cancelled when the Exploration Systems Architecture Study evolved into the Constellation Program, which is now being debated in the U.S. Congressional appropriations process. ${ }^{3}$

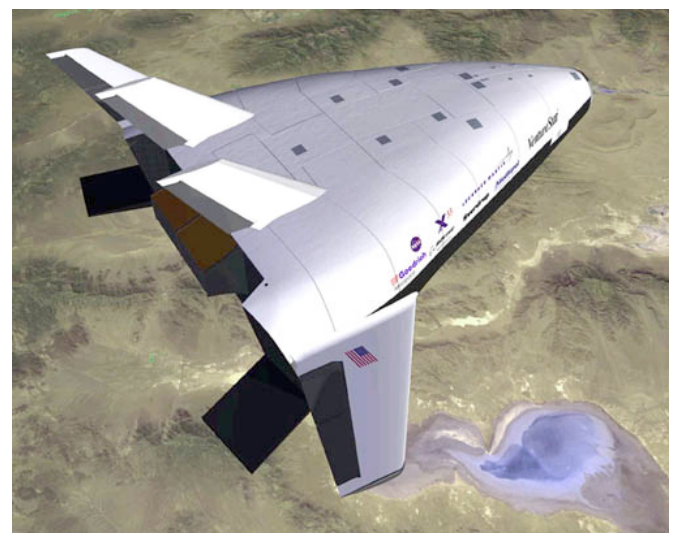

Figure 3. NASA concept of the $\mathrm{X}-33$ flight demonstration vehicle.

When faced with such obstacles and the seeming setbacks that naturally come with new starts, the wheels of progress slow down, allowing budget issues and politics to make costly course corrections that too often result in derailed efforts. That is not to say that the lessons are not worthwhile, but it is difficult to grow a tree when digging up the seed on a regular basis. In a climate of shrinking budgets and timelines, risk management has become a survival tactic and the only variable in a continually changing business model. We can find a thousand reasons why to point a finger and at whom, but looking in the mirror, at our own reflection, is the most revealing view. Why have we allowed the political climate to make us risk adverse? How can we realize a new space transportation system's first flight if we cannot find it within ourselves to learn that the art of engineering a complex system is about the art of compromise, about accepting and communicating risk relative to high-performance systems? These cultural norms are as important to equipping the aerospace engineer to break the start-stop-restart cycle as is political will.

When surveying the private space industry today, it is a tempting prospect to join their ranks and make things happen in quick time (Figure 4). Saturn V architect and the first Director of the Marshall Space Flight Center Dr. Werner Von Braun said repeatedly, getting hands-on experience and finding out firsthand what makes things tick, especially in the high-stakes world of propulsion systems, is essential to understanding how things work. ${ }^{4}$ 
Dr. von Braun also encouraged and rewarded the healthy face-to-face debates that ferret out problems and lead to solid engineering solutions to stakeholder requirements that often become moving targets. NASA's 50 years of experience with highly complex systems, from the Saturn V to the Space Shuttle to the International Space Station, has formed a fantastic platform of knowledge about living and operating in space. The trick is to selectively apply only the relevant data and not all the bells and whistles that consume performance margins and management reserves. Perhaps organizations with decades of history can position for future exploration breakthroughs by learning from their counterparts' agility and the innovative climate they routinely offer their employees.

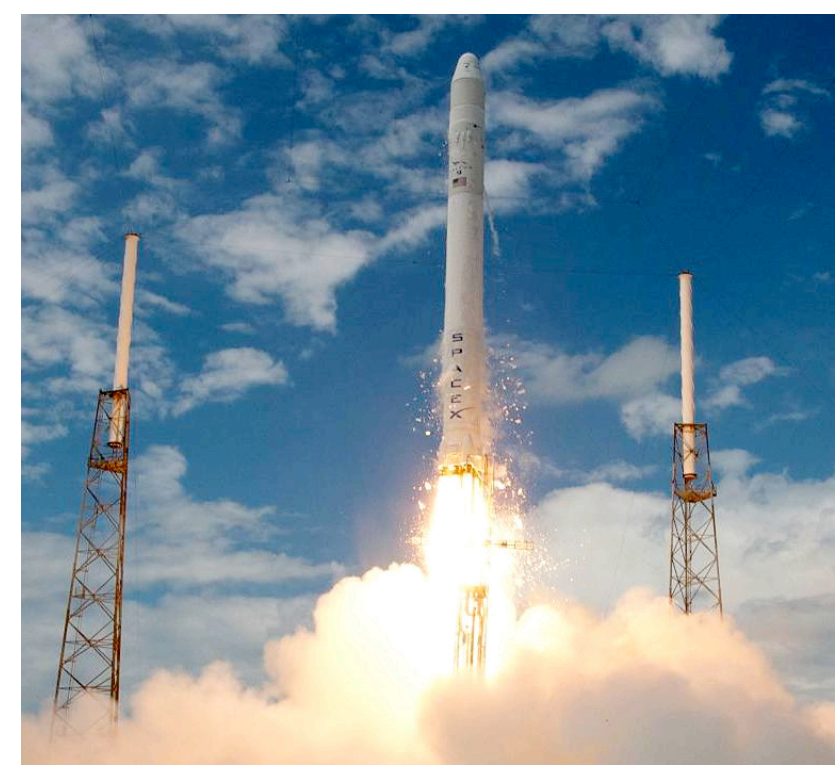

Figure 4. The Space X Falcon 9 inaugural launch in June 2010.

The question is how to unburden the mental model that has been created, to minimize the ever-growing set of constraints, hurdles, and attitudes that blocks us from completing what we begin, to realize the fruits of our labor. The Engineering Directorate at NASA's Marshall Space Flight Center serves as a microcosm for observations and applying simple approaches to retraining a risk-averse culture created from too many electronic tools and channels (noise in the system), too little direct communication (blogs, e-mail, Twitter, Facebook, etc.), and too many processes (regulations, specifications, procedures, etc.) that may stifle innovation. Helpful conveniences and thoughtful regulations should not hinder the engineering practice but, rather, unleash the potential within the professional workforce equipped to break through self-imposed limitations that are compounded by the start-stoprestart cycle.

\section{Learning to Fail: The Art of Engineering}

Sustainable space exploration is a new mantra that applies not only to hardware and software, but to the workforce that makes America's aerospace industry the powerhouse it has become over the last 50 years. The very act of starting-stopping-restarting drains energy from the minds and hands of those who deliver the space missions that make this discussion possible. The art of systems engineering, combined with the science of systems management, are two methods to correctly characterize technical requirements and to scope the task. They also create a foundation for organizational communication. 
Planning programmatic content to deliver incremental value will go a long way toward sustainability, but getting to first flight is almost as hard as escaping the "gravity well" to get to orbit. The talented technical people who devote their careers to this pursuit depend on managers to make wise decisions based on realistic data and with cognizance of the political and budgetary constraints. Too often, they become entrapped by these forces, which are out of their hands, and retreat to analyzing data rather than keeping their hands dirty, reflecting a risk-averse culture that may have trouble executing a program that is fully funded with a definite goal and timeline and budget to match. As stated in an article on Innovation in Aerospace and Defense, "What needs to happen is that industry stakeholders must undergo - or again, perhaps simply rediscover — a cultural shift from 'risk-averse' to 'risk-aware.' Risk-awareness involves understanding and evaluating risk as thoroughly as possible and then minimizing it by the choice of appropriate tools and approaches. Most importantly, risk-awareness means a commitment to accept risk once the measures to mitigate and minimize it have been established and implemented."

Ultimately, it is each individual's responsibility to communicate with team members, to articulate the workings of complex, high-performance systems. It is the individual's technical and interpersonal competencies, combined with a willingness to compromise, which make the team's technical products reliable and affordable, despite factors that are beyond immediate control. We must learn to trust and respect one another, and the roles we each serve, to find effective solutions. Applying these principles to aerospace programs and projects will be a major step toward breaking the cycle that affects not only the progress we demonstrate, but the decisions that engineers make relative to their chosen field. Managers can do only so much - it is up to the workforce to deliver. The caveat is that mangers often over-promise, setting up the workforce to under-deliver. This is not the win-win situation that everyone involved deserves.

In space transportation, performance is king and engineers, by their very nature, are a community of improvers, which collectively stretches schedules and budgets. Today's reality requires us to shift to a schedule-is-king approach, not add risk and schedule associated with trade studies to get performance improvements. Engineering is a team sport that is played on multiple fields. While converting the office infrastructure from paper to digital data, the conversation often revolved around information technology tools. Over the past 5 years, Marshall's Engineering Directorate has put in place an extensive digital space transportation system enterprise. Organizationally, a network of Chief Engineers is in place throughout the program and project customers, from small technology development satellites and payloads, to full-blown science racks and air and water recycling capabilities for the International Space Station (Figure 5). But these management related conventions only go so far to help workers accept a reasonable level of risk, which is essential to pushing the edges of physics, as well as continually surveying existing systems for anomalous signals. Beyond listening to the hardware and software, we must learn to listen to each other, to respect the other team members' opinions and the functions they serve. This team norm is best taught through example.

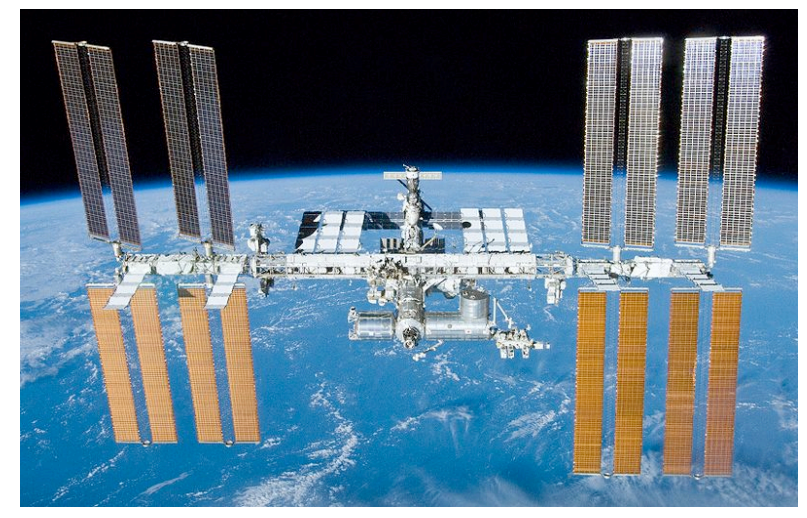

Figure 5. The International Space Station is an engineering feat. 


\section{Communicating the Engineering Continuum}

The workforce has continued to deliver excellent products and services on time and within budget, but it is often the case that the start-stop-restart cycle will prevail. Personnel hear excessive noise in the system, often believing what they see and hear in the media is more valid than what they hear and see around them. They are overprocessed, meaning they get so much information - it is hard to distinguish what is important. The tools often impede face-to-face communication - body language and other non-verbal cues from real-time interactions are invaluable.

This underscores the importance of regular and persistent communication as a key strategy in ways that allow for two-way feedback. Employee surveys point to the fact that they want to hear news from their team leads and supervisors. Setting that expectation for leads and supervisors is the job of management. The Engineering Directorate's leadership is graded on the basis of performance plans, which reflect the expectations of NASA leadership at the Headquarters level. NASA's education and outreach communication goals could be the subject of a separate paper; for this purpose, internal communication is one channel for mitigating the risk of getting to first flight. This is a powerful phrase that evokes a long, hard road through programmatic and technical battles and breakthroughs.

Probably the single most important strategy is communication, but what do we communicate? Recent experiences with the second President Bush's exploration initiative, the Constellation Program which is now being debated in the Congressional FY11 budget process, leads us to the next strategy, and that is to create a sense of continuity from one political administration to the next by focusing on the underlying work.

Engineering can be hurried - but only to a point. The one-of-a-kind hardware and software systems that aerospace engineers produce take time to grow from an idea to an innovation. The prototypical products that the space program demands require intense effort. Giving these employees a sense of continuity across political lines will help aerospace engineers feel successful, despite the many changes to which they are their work are subjected. This strategy, in turn, should increase job satisfaction, while somewhat mitigating the morale risk that comes with terminating a major undertaking.

There are many examples of this phenomenon, where an effort that was begun for one project winds up in another one altogether. Unless attention is paid and these uplifting, and grounding, stories are told in a consistent manner, the successes that take place in the span of a career, and others that pass on from one generation to the next, may be lost. This strategy requires that managers make story-telling a valued team norm as a way to focus on individual and collective successes rather than on setbacks and cancellations. It places importance on risk management by sharing lessons lived and learning from our unique set of experiences.

One example can be found in the story of the RS-68 engine that flies today on the Delta IV evolved expendable launch vehicle (EELV) - a U.S. Air Force (USAF) asset. Billed as the largest hydrogen-fueled engine in the world, its roots trace to the National Launch System (NLS) in the 1990s. NLS, as a subset of the first President Bush's Space Exploration Initiative, was focused on developing a follow on to the Space Shuttle, with a cost-effective footprint that could benefit both NASA and the USAF. NLS included the Advanced Launch System (ALS), to develop the first liquid fueled U.S. engine since the Space Shuttle Main Engine decades earlier. Throughout the course of the NLS/ALS, the high payoff Space Transportation Main Engine (STME) was the focus for Earth orbit rendezvous and future missions to Mars. ${ }^{6}$ Figures of merit included simplicity of design and affordable production and maintenance costs.

This made a lot of sense, especially to NASA engineers and their industry partners, many of whom were directly involved in the SSME design, development, testing, and operation/maintenance. By the time the Republicans left office and President Clinton moved in, the NLS Program was cancelled in 1992 and replaced in 1994 with the Access to Space Study and the Reusable Launch Vehicle Program in the mid-1990s, with its X-33 and $\mathrm{X}-34$ flight demonstrator projects. ${ }^{7,8}$ 
Despite the fact that STME hardware had actually been tested, the political climate changed; however, that engine, which was to have been human-rated to carry crews, became the foundation for the USAF's RS-68, which began launching satellite delivery missions in 2002 (Figure 6). The expendable RS-68 delivers 650k lb thrust at sea level and a specific impulse of $410 \mathrm{isp}$, and has been true to its heritage, with simplified manufacturing and 80 percent fewer parts than the reusable SSME.

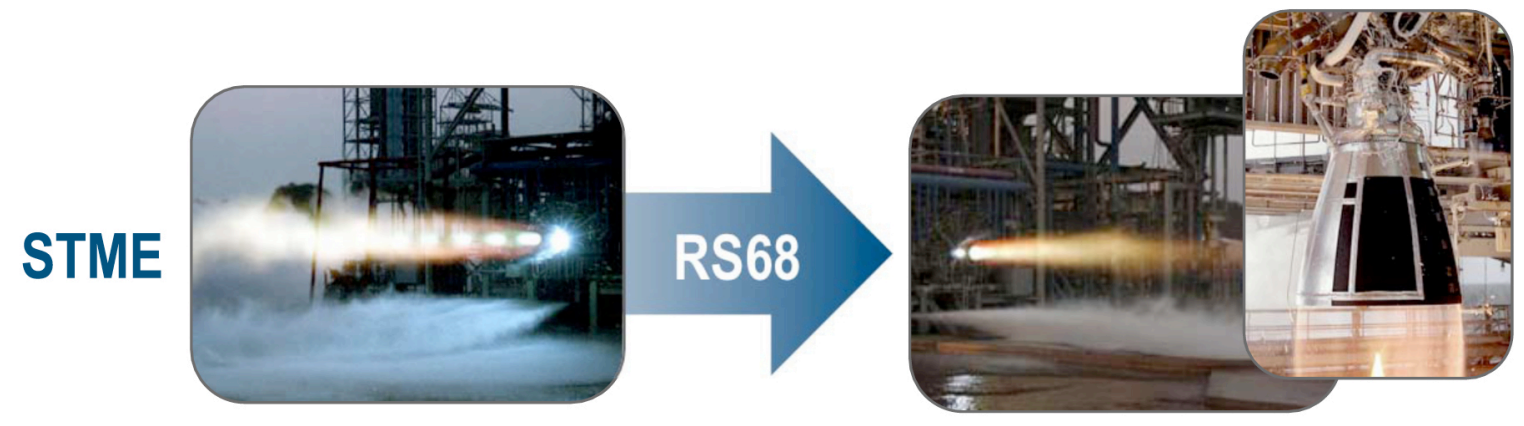

Figure 6. STME to RS-68 engine evolution.

While there are numerous other examples, the fact is that consistently communicating continuity is a strategy that can be implemented in a number of ways without losing sight of the politics that rightly shape America's space agenda. An excellent example of effective organizational communication is that evidenced by Dr. von Braun. An academic study of his methods contained in "Organizational Communication Imperatives: Lessons of the Space Program" provides many recipes for communicating well and often across a broad range of workers. It documents his "keep your hands dirty" philosophy to rocket building and puts the role of systems engineer into sharp focus. ${ }^{10}$

In Marshall Engineering and across NASA, a network of Chief Engineers serves to integrate a broad spectrum of work. Chief Engineers are embedded throughout the programs and projects served by the Engineering Directorate, which is a matrixed organization, to integrate technical solutions on time and within budget. Chief Engineers, who are on par with project managers, are responsible for integrating more than hardware and software - they serve as a communications conduit from the front lines of design and development to the rear echelon of accountability reporting. The Chief Engineers and discipline-based communities of practice are two well-known means to communicate both formally and informally.

As mentioned earlier, another way to prepare the workforce to get to first flight is to plan realistic programmatic content that delivers measurable and meaningful milestones as a way to give value to stakeholders, while grounding aerospace engineers in incremental successes. By adding to the catalog of space transportation technologies, engineers get a sense of accomplishment. This is paramount to the very survival of engineering over the long run; employers must be competitive, as today's junior engineer has global options, and opportunities to hire are infrequent.

Equipping space engineers to break the cycle of start-stop-restart is paramount to taking space exploration beyond Earth orbit, stimulating technologies, economies, and imaginations. Creating a learning culture, where the creativity that comes from discovering solutions to the challenges of space flight, is the goal of Marshall Engineering's leadership. Helping the workforce to confidently apply technical capability and credibility, and grapple with the reality that there is more than one right answer to most questions/problems, are hard lessons to teach ... and to learn. Consistently communicating continuity through a robust oral history and plain old personal dialogue is the ultimate strategy to equip aerospace engineers to create new habits while breaking the bonds of programmatic dogma. 


\section{Conclusion}

The U.S. aerospace industry is threatened by a number of external forces, from changing governmental priorities to cheaper foreign labor. Current space plans are creating an environment for entrepreneurial interests to have a larger market share, delivering cargo to the Space Station, for example, while NASA heads the design of a new heavy lift launch vehicle that can reopen the human exploration of space beyond Earth orbit (Figure 7).

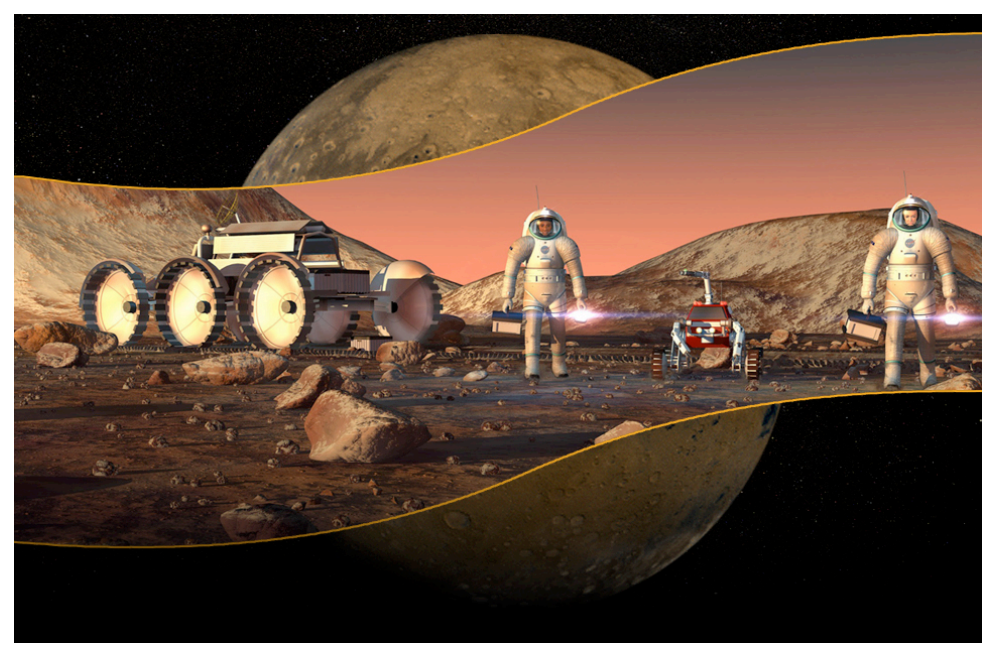

Figure 7. NASA concept of Mars exploration.

The keys to success include learning the art of engineering a system, compromise, and accepting and communicating risk relative to complex, high-performance systems. Developing engineers who are confident risk takers and who are able to supplant ambiguous programmatic goals with hands-on technical experience, is no less than the task at hand, especially for those who have been subjected to the constant change of the last few decades. As the Space Shuttle retires in 2011, bringing not just lessons, but knowledge and experience to bear, is a key riskreduction strategy. Breaking the start-stop-restart cycle is not just a political challenge, but a personal growth opportunity, especially when coupled the understanding that work done in the past is an important part of building the foundation for America's future in space.

American Institute of Aeronautics and Astronautics 


\section{References}

1. Launching the $21^{\text {st }}$ Century American Aerospace Workforce, Aerospace Industries Association, December 2008.

2. National Space Policy, www.ostp.gov, June 28, 2008.

3. Exploration Systems Architecture Study (ESAS), Final Report, NASA TM-2005-214062, November 2005.

4. Tompkins, Phillip, Organizational Communication Imperatives: Lessons from the Space Program, Roxbury Publishing Company, 1992.

5. Rivers, Charles, "Innovation in Aerospace and Defense," Charles Rivers \& Associate, October 28, 2009.

6. The Road to Ares V - A short history, www.Spacelaunchreport.com/sdv.html

7. Heuther, Jacob, et al., "Space Shuttle to Reusable Launch Vehicle," 1995, http://science.ksc.nasa.gov/shuttle/rlvhq10.htm

8. Wood, Byron, "Propulsion for the $21^{\text {st }}$ Century - RS-68," $38^{\text {th }}$ Joint Liquid Propulsion Conference, July 2002.

9. Andrews Space and Technology, RS-68 Summary, www.spaceandtech.com/spacedata/engines/rs68 sum.shtml

10. Tompkins, Organizational Communication Imperatives. 


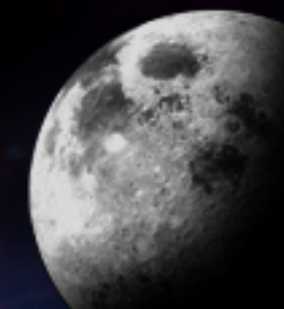

Getting to First Flight:

Equipping Space Engineers to Break the Start-Stop-Restart Cycle
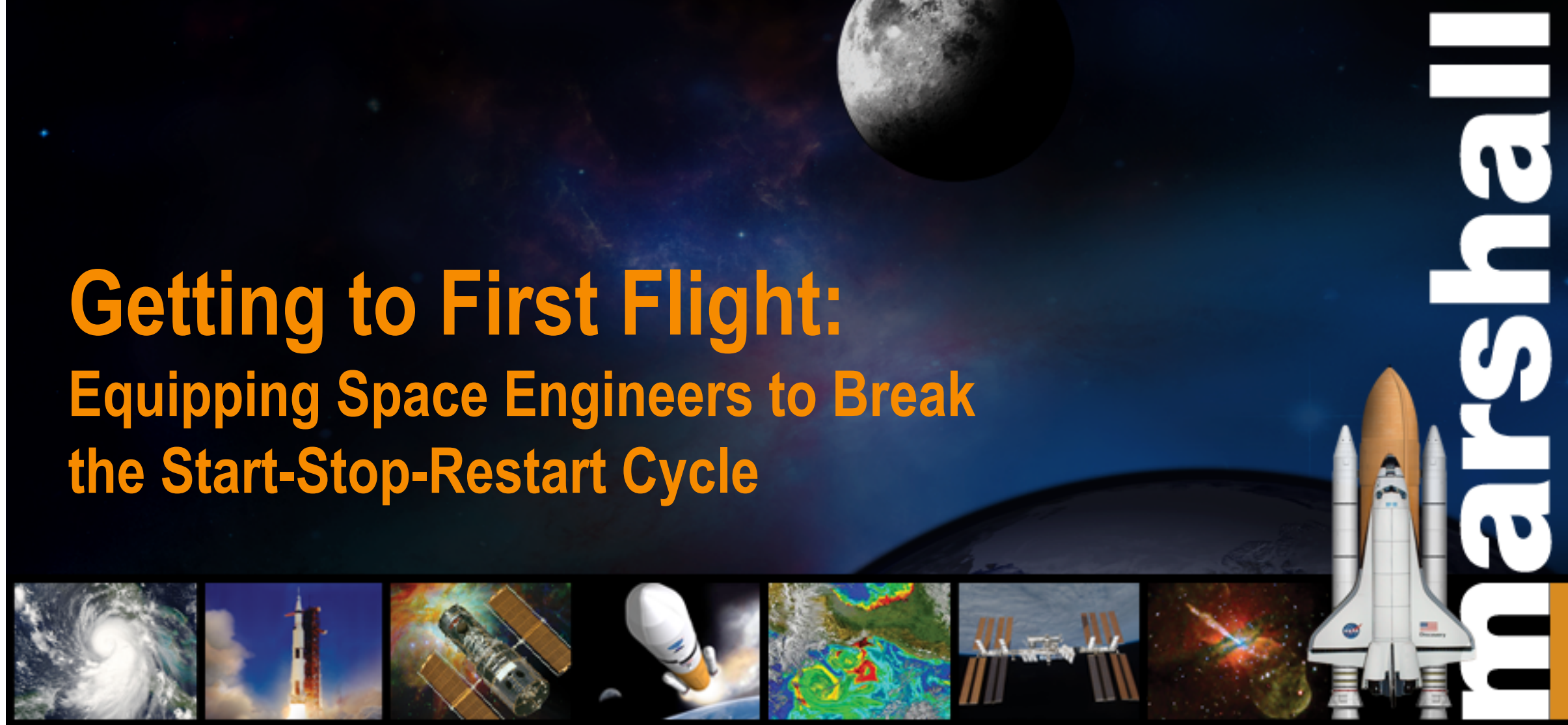
Engineering Directorate NASA Marshall Space Flight Center 


\section{Agenda}

- NASA: Why America Explores Space

- Marshall Space Flight Center Capabilities

- Marshall Engineering

- The Workforce Environment

- NASA Programs are Tied to Administration Cycles

- Consistently Communicate the Engineering Continuum

- Plan Programmatic Content to Deliver Incremental Capability

- Communicate Significant Accomplishments

- Mission Success Requires Talent and Tenacity 


\section{NASA: Why America Explores Space}
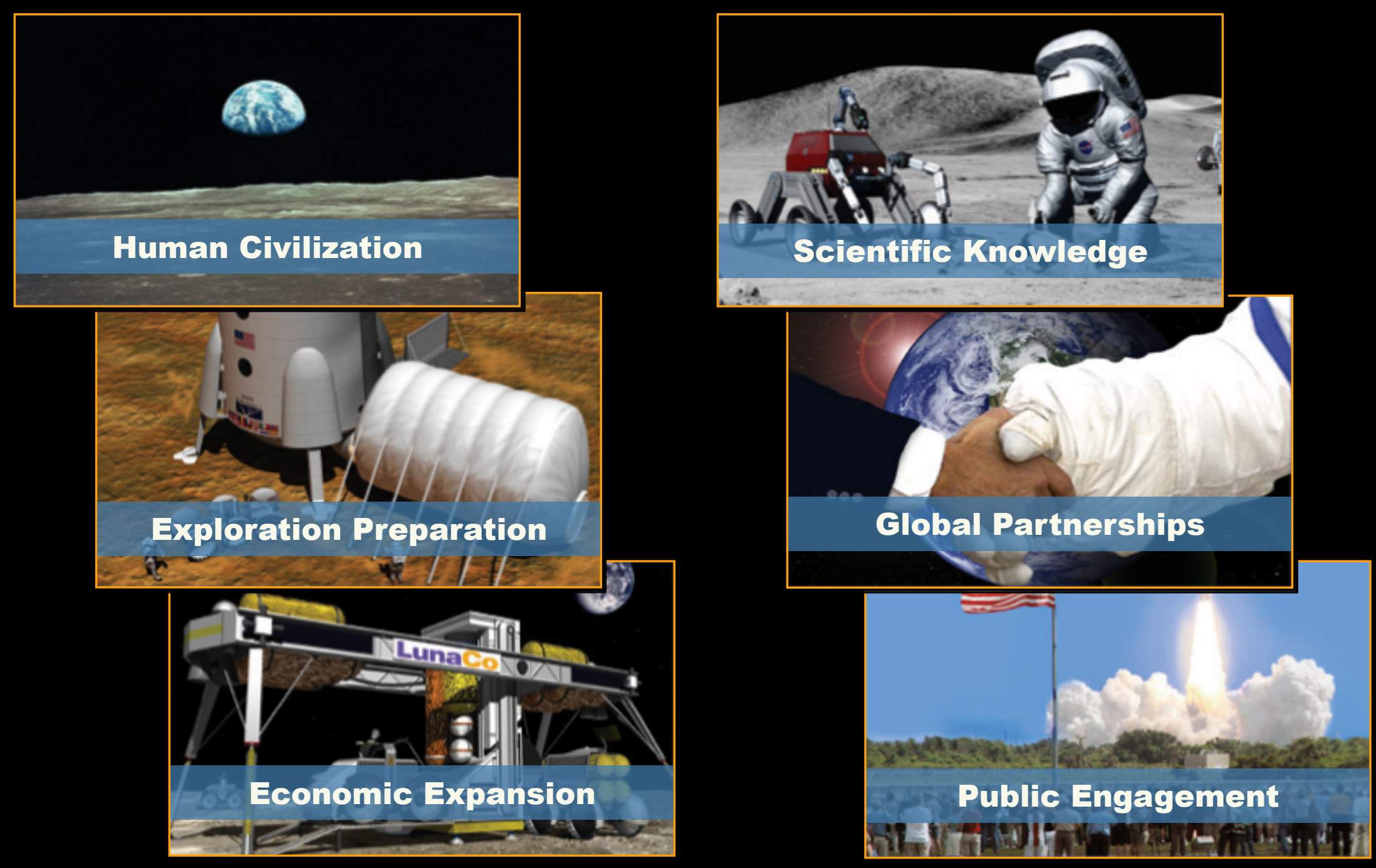

Opening New Frontiers 


\section{Marshall Space Flight Center Capabilities}

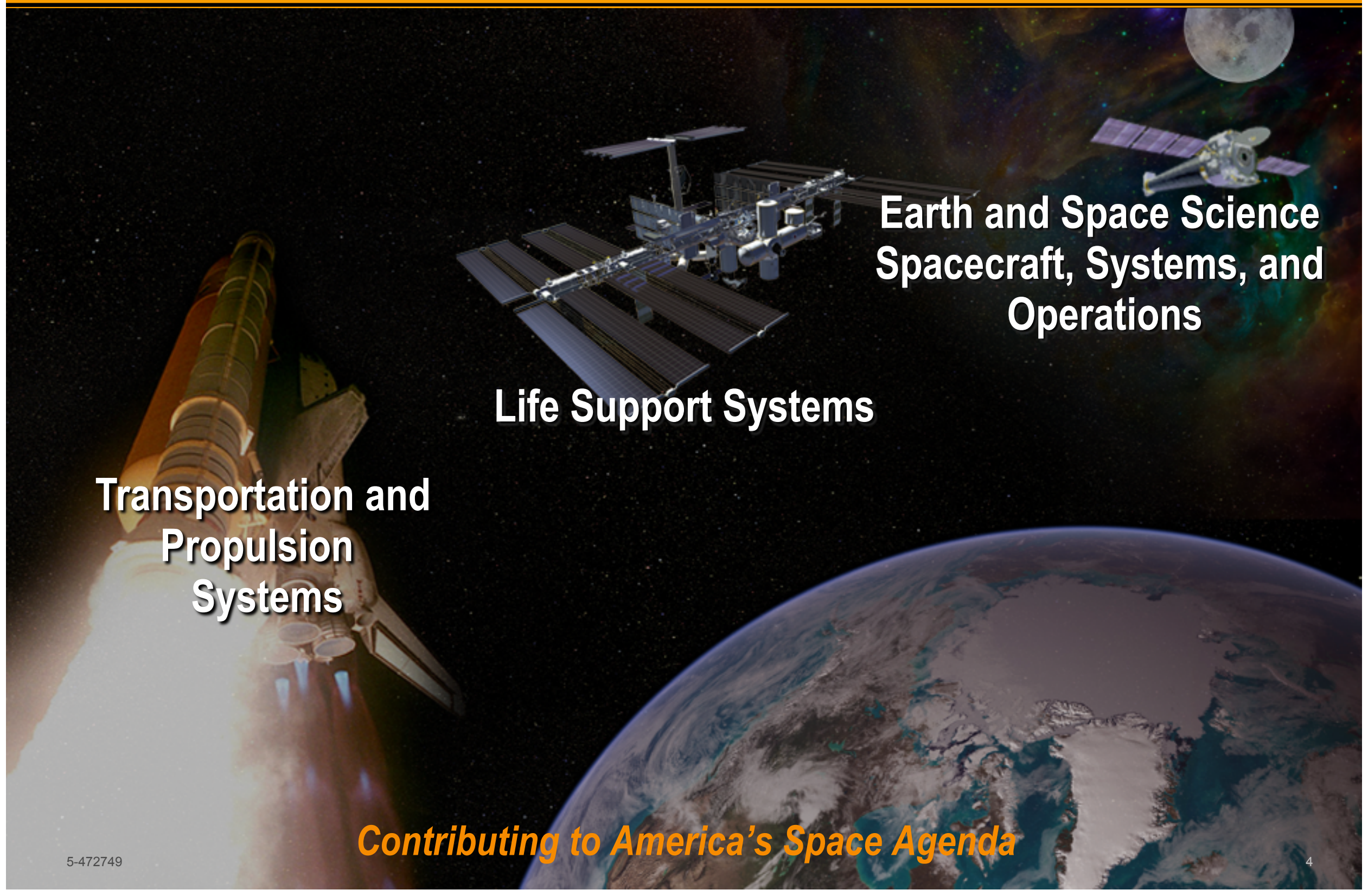




\section{Marshall Engineering}

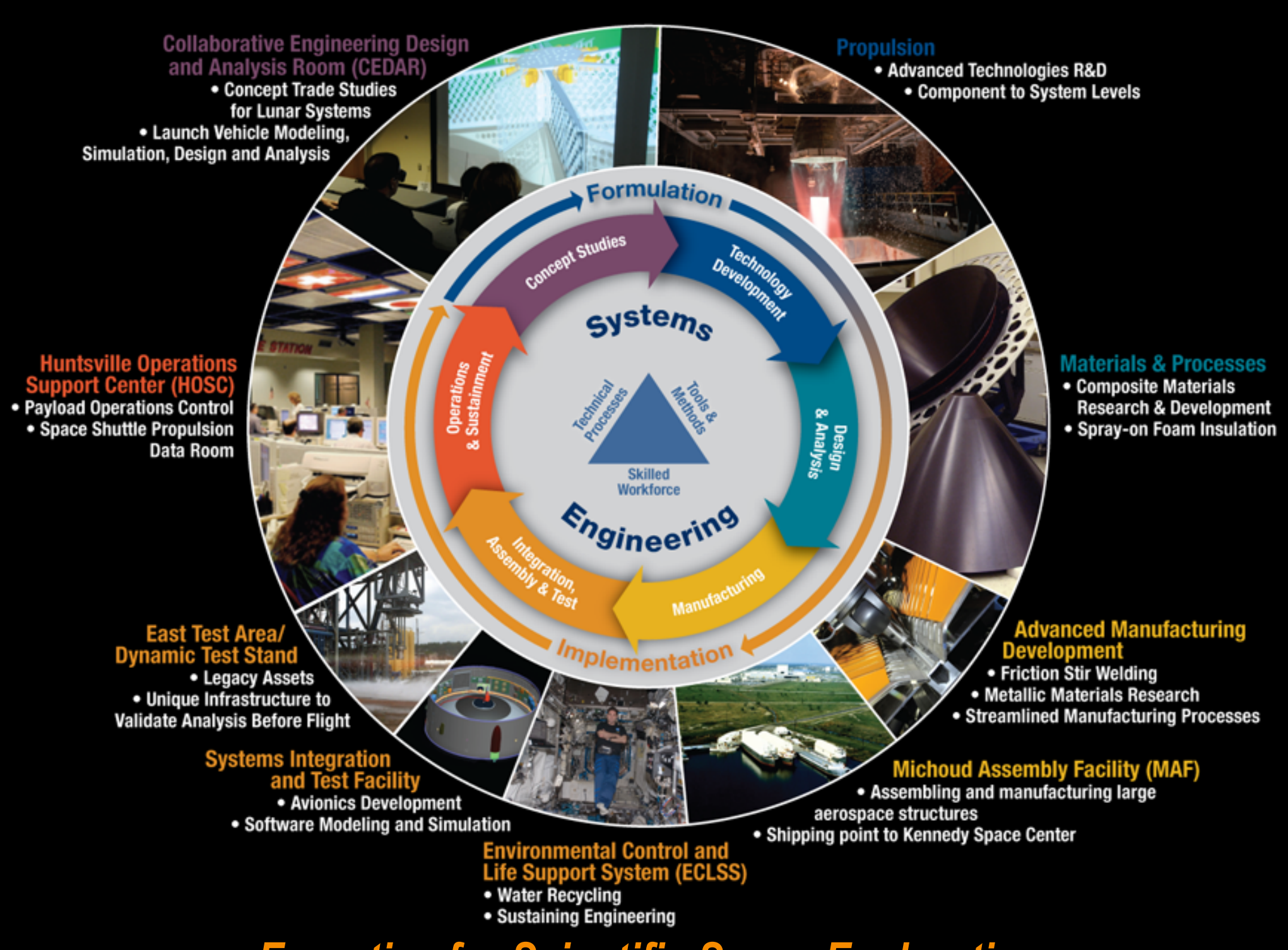

Expertise for Scientific Space Exploration 


\section{The Workforce Environment}

The NASA Age Distribution Contrasted With the U.S. Workforce (2008)

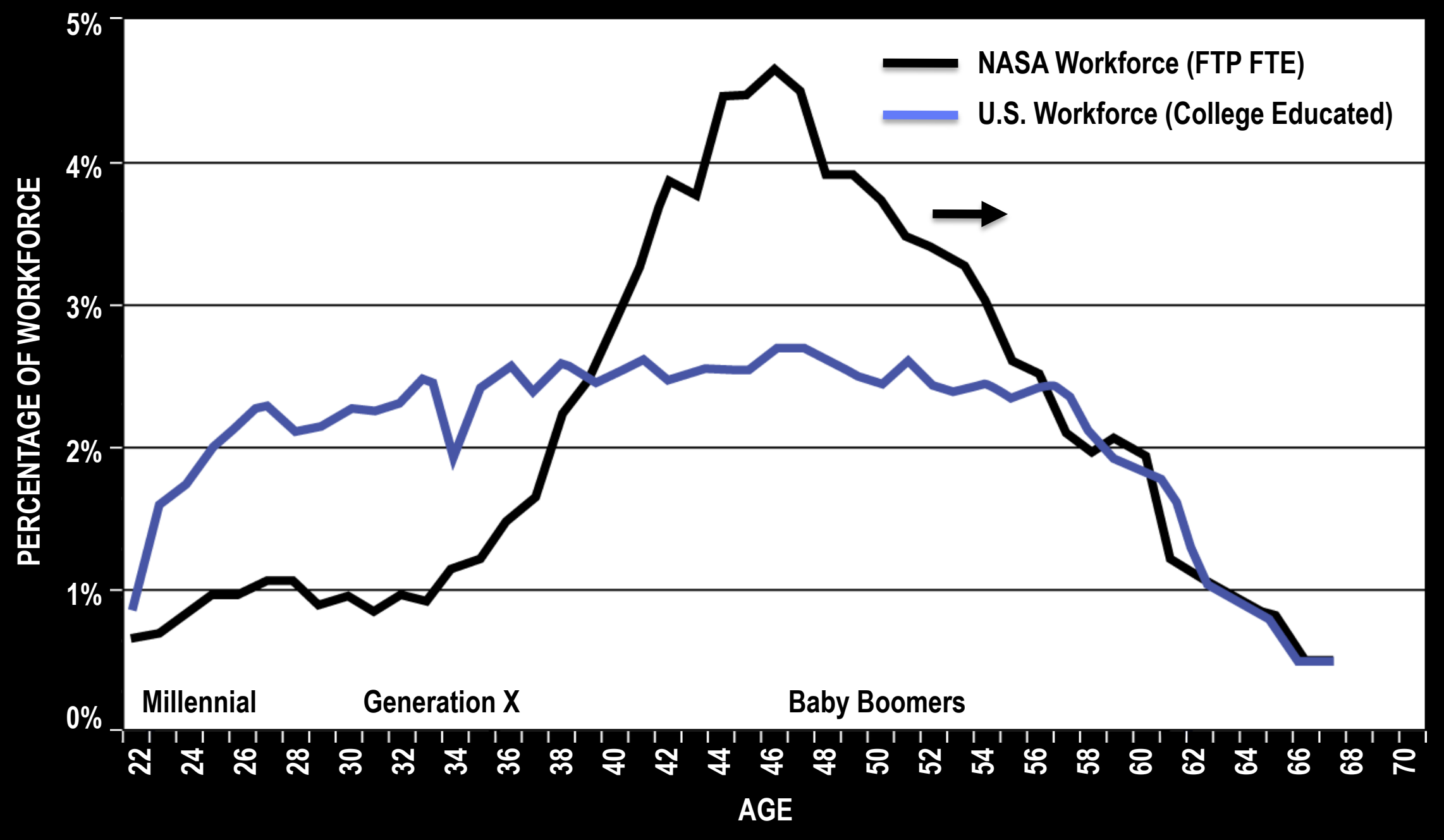

Need the Next Generation of Engineers for a New Age of Exploration 


\section{NASA Programs are Tied to Administration Cycles}

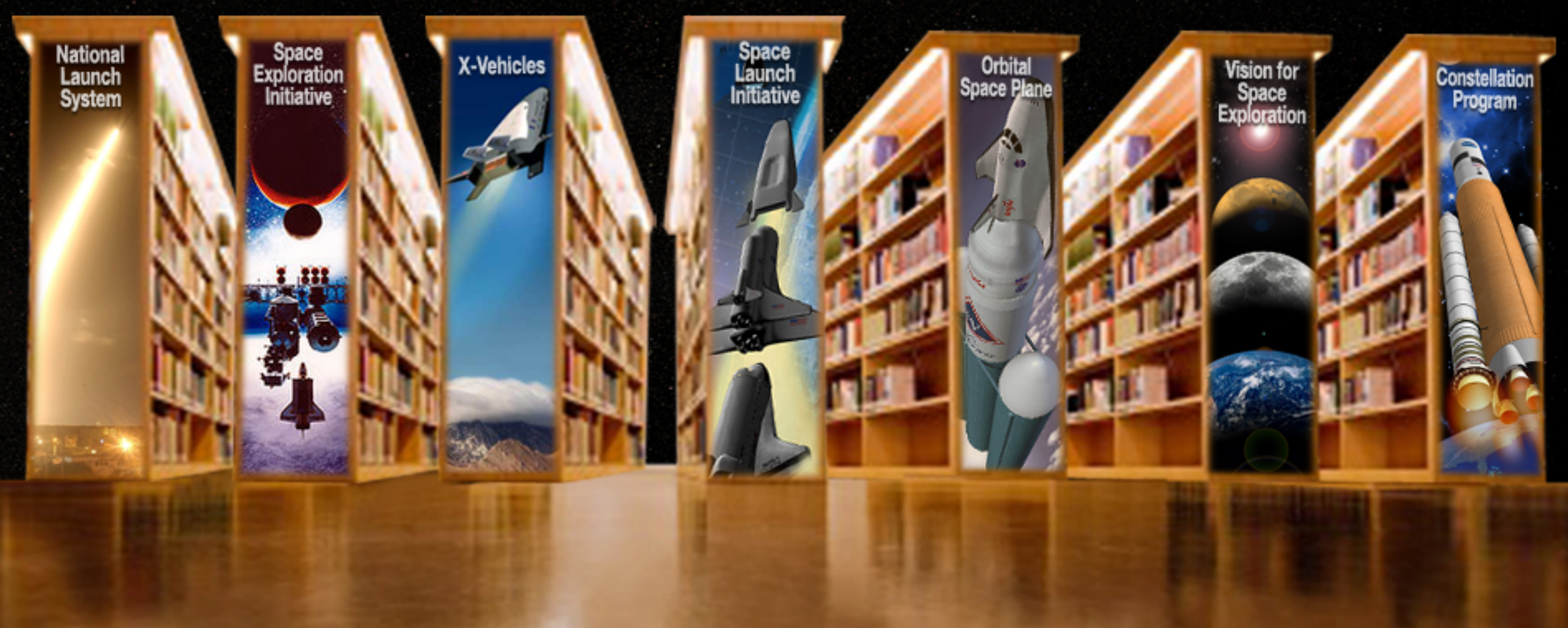


Consistently Communicate the Engineering Continuum

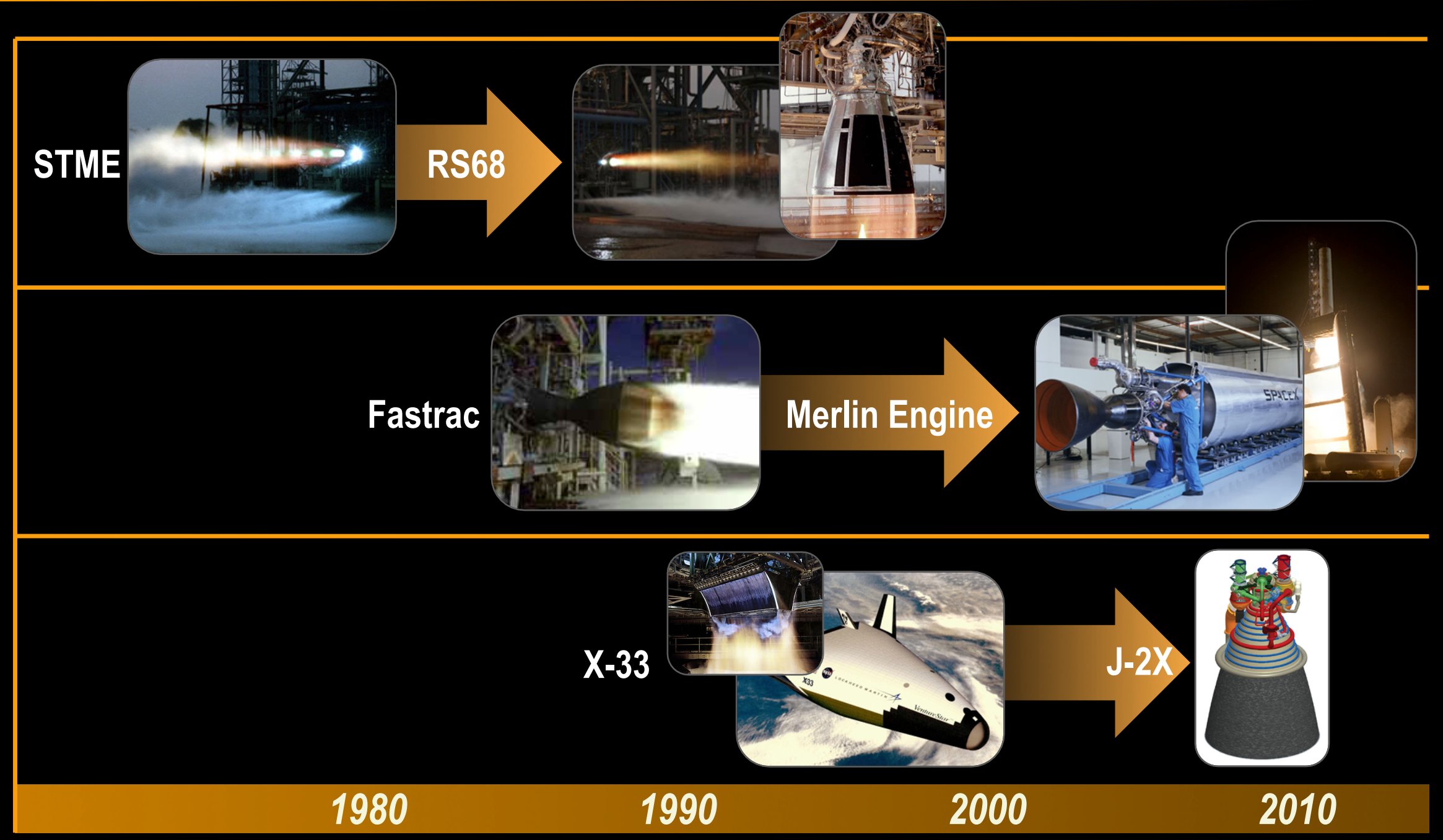

Technical Successes Transcend the Start-Stop-Restart Cycles 


\section{Plan Programmatic Content to Deliver Incremental Capability}

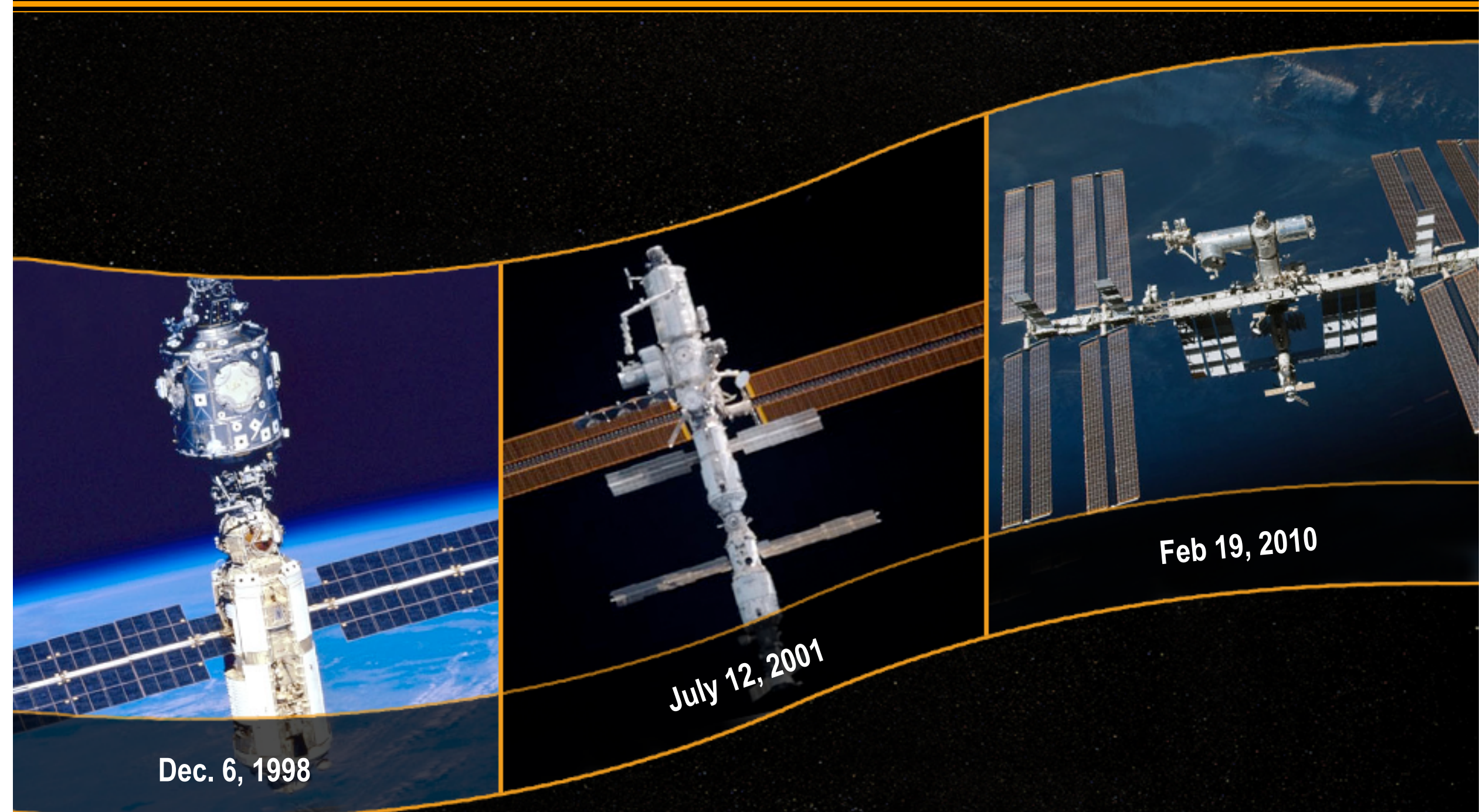




\section{Communicate Significant Accomplishments}

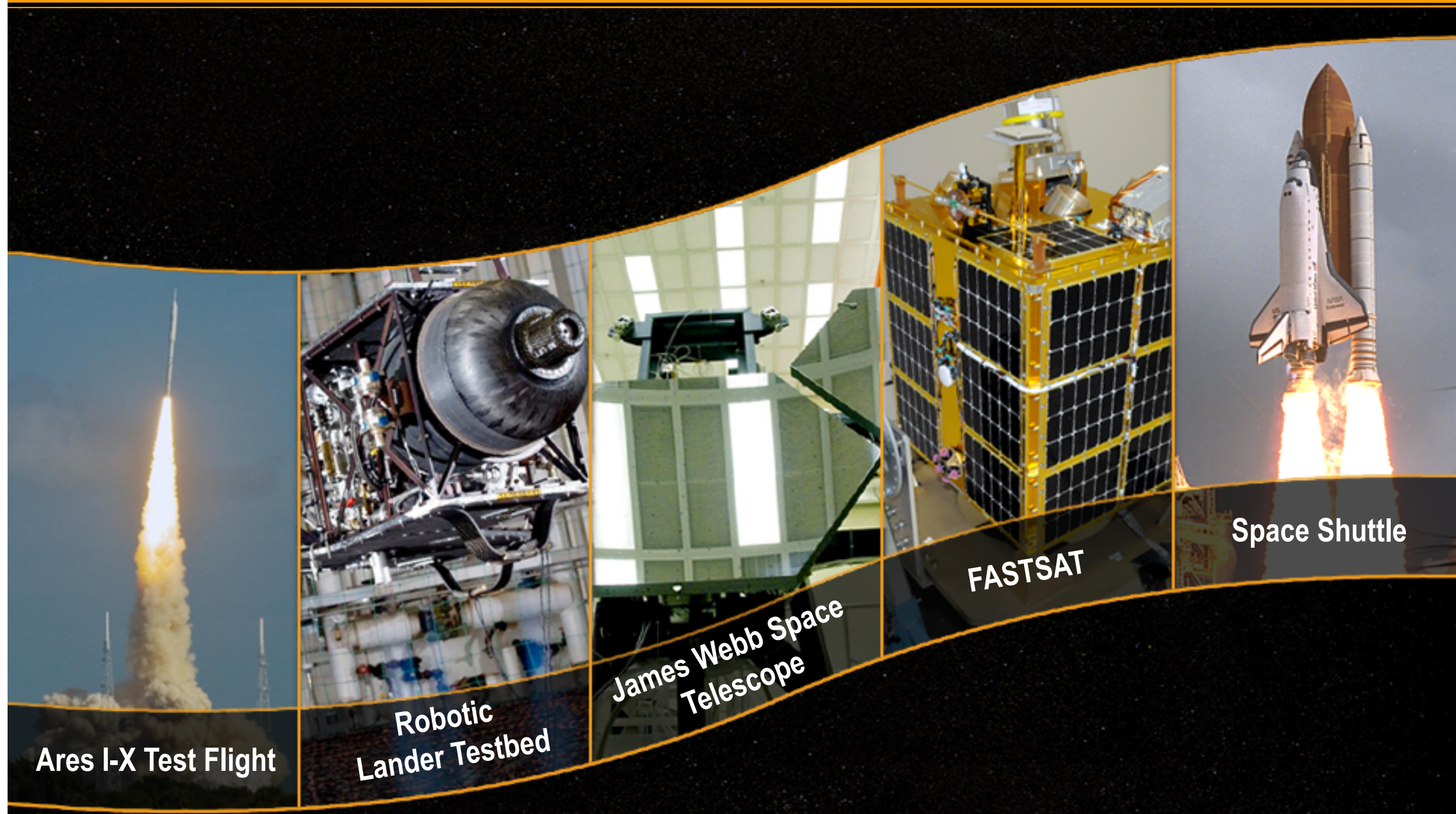

Focus the Workforce on Successes 


\section{Mission Success Requires Talent and Tenacity}

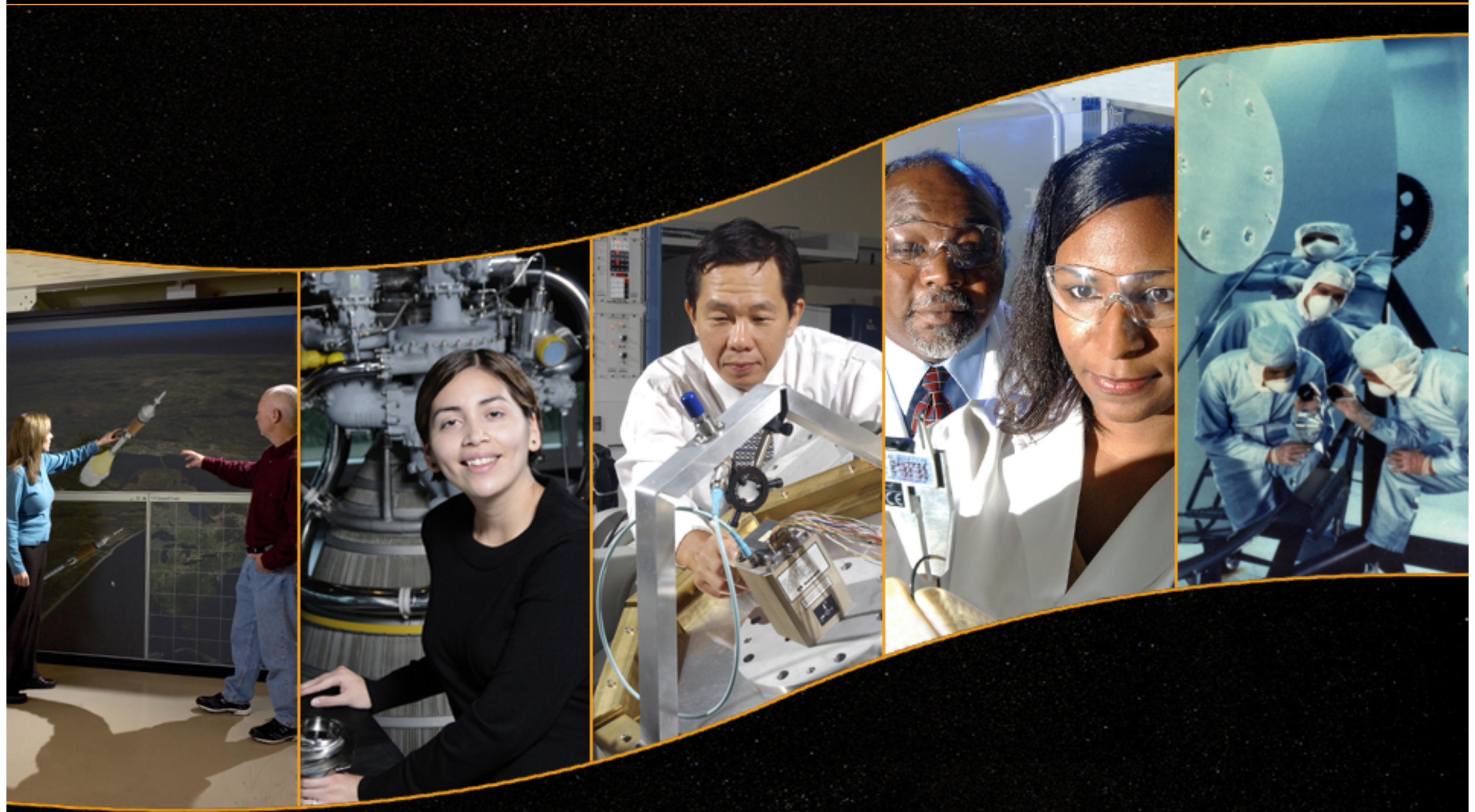




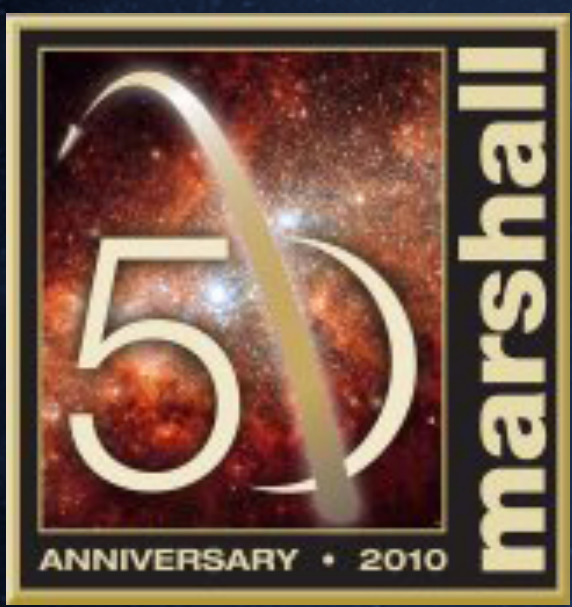

For more information:

www.nasa.gov 